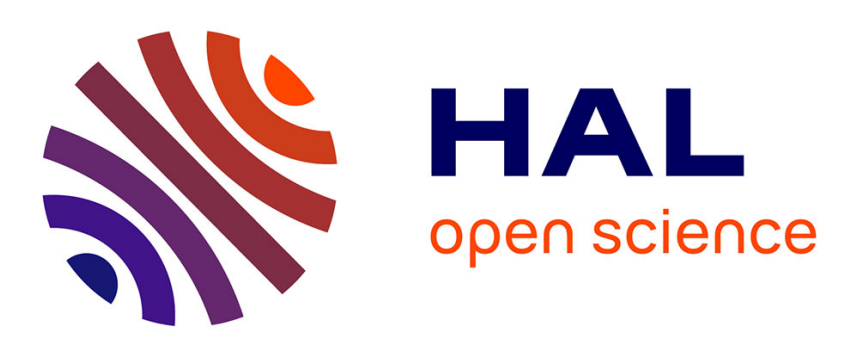

\title{
Balancing situativity and formality: the importance of relating a formal language to interactive graphics in logic instruction
}

Jelke van Der Pal, Tessa Eysink

\section{To cite this version:}

Jelke van Der Pal, Tessa Eysink. Balancing situativity and formality: the importance of relating a formal language to interactive graphics in logic instruction. Learning and Instruction, 1999, 9 (4), pp.327-341. 10.1016/S0959-4752(98)00050-4 . hal-00197363

HAL Id: hal-00197363

https://telearn.archives-ouvertes.fr/hal-00197363

Submitted on 14 Dec 2007

HAL is a multi-disciplinary open access archive for the deposit and dissemination of scientific research documents, whether they are published or not. The documents may come from teaching and research institutions in France or abroad, or from public or private research centers.
L'archive ouverte pluridisciplinaire HAL, est destinée au dépôt et à la diffusion de documents scientifiques de niveau recherche, publiés ou non, émanant des établissements d'enseignement et de recherche français ou étrangers, des laboratoires publics ou privés. 
Van der Pal, J., \& Eysink, T. (1999). Balancing situativity and formality: The importance of relating a formal language to interactive graphics in logic instruction. Learning and Instruction, 9, 327-341. This is the author's version of the journal article, published in Learning and Instruction (C) Elsevier Ltd. 1999, http://dx.doi.org/10.1016/S0959-4752(98)00050-4

Balancing Situativity and Formality:

The Importance of Relating a Formal Language to Interactive Graphics

in Logic Instruction

Jelke van der Pal

Tessa Eysink

Instructional Technology

University of Twente, The Netherlands

present address first author:

National Aerospace Laboratory NLR

Anthony Fokkerweg 2

1059 BM Amsterdam

The Netherlands

email:pal@nlr.nl

running head: 
abstract

A situated cognition theory is presented in which situated learning is viewed from a Vygotskian perspective: the developmental situativity theory. It is assumed that learning is basically a non-symbolic inductive process that is greatly enhanced by formal systems which act as tools. Instruction should provide students with an environment containing elements to allow for situated activity as well as with appropriate formal tools. Tarski's World, which is an instructional Interactive Graphical Representation System in formal logic is an example of such instruction. The developmental situativity theory was supported empirically: Tarski’s World was found to facilitate conditional reasoning, in contrast to instruction that is based on only-situated or only-formal tasks. 
Introduction

Any expectation that a certain training programme may facilitate abstract conditional reasoning is audacious, as it has proved to be extremely difficult to establish such understanding (for a review of the abundant literature, see Evans, Newstead \& Byrne, 1993). Yet, to facilitate conditional reasoning is precisely one of the promises of Tarski's World (Barwise \& Etchemendy, 1990), an Interactive Graphical Representation System (IGRS) intended as an introduction to formal logic, with a strong focus on semantical aspects of logic. As the logical theory behind situation semantics (Barwise \& Perry, 1983) may have inspired Barwise and Etchemendy to develop courseware in which statements refer to concrete situations, it is not surprising to find Greeno (1990) putting Tarski's World into a situated cognition realm.

Situated cognition as it was debated within the field of instructional science in the late eighties (Brown, Collins \& Duguid, 1989) provided a new escape route from formal education. Within purely formal education, knowledge is taken to be a static set of abstract concepts and procedures which are assumed to be taught by exposing their formal representations to the students in one way or another. In contrast, instruction based on situated cognition notions is designed in such a way that the student can learn in an appropriate social and real-life context, through which knowledge is not transmitted to the student, but constructed through authentic activity and social interaction. Knowledge, therefore, is a dynamic by-product of the individual - environment interaction. Although education based on situated cognition (for a recent overview see Choi \& Hannafin, 1995) may be refreshing in itself, its novelty is questionable given that it might merely represent another repetition of history in which some formal education is counterbalanced with some naturalistic education. By pointing to Tarski's World, Greeno illustrated, perhaps unintentionally, that the formalist - naturalist debate may not be really important at the 
instructional level. Tarski's World has formal aspects and yet it elicits situated cognition from students.

A more severe problem is that the psychology behind situated cognition has been neglected. In the perception of instructional scientists, there can only be situated cognition when the learning situation has obvious authentic characteristics. Consequently, for educational purposes, situated cognition seems to be a function of external, nonpsychological variables. This is unfortunate, because tasks can be construed to facilitate situated cognition without being authentic, whereas authentic tasks may hardly seem to involve situated cognition (as in logic). Without a psychological grounding, situated cognition leads to inaccurate claims and mistaken educational implications (Anderson, Reder \& Simon, 1996), while the determination of appropriate learning environments and tasks is intuitive.

This recognition has led to the formulation of an adapted version of situated cognition, which is labelled the 'developmental situativity theory' (Van der Pal, 1995). This theory attempts to resolve the troublesome relationship between formal and situated elements of most situated cognition stances (Bereiter, 1995). After introducing the developmental situativity theory, the main results of a study focusing on the theory's central research question will be described. Tarski’s World will be used for that purpose.

\section{The Developmental Situativity Theory}

It is assumed that a situated cognition theory that aims at the relation of formal and situated elements within cognition, action, and learning cannot be accurate without clarifying the psychological processes behind them. A start for a psychological grounding for situated cognition can be found in a number of situated action theories (Greeno, 1989; Clancey, 1993; Greeno \& MSMTA Project Group, 1998), which are based on similar assumptions as situated cognition theories but try to provide a more complete model of 
human activity. The basic assumption is that cognition or action in most everyday life situations is unmediated by representation. In our understanding of the situated action stance, no distinction is to be made between a perception and an object, as the observer can only deal with perceived information. This implies that on a psychological level the perceived information does not refer to the object, it is the object. Activity towards the object is not only based upon but also intertwines with the perceived information (i.e., the object itself). That is why activity is called 'direct' and 'situated'. There is no symbolic layer between perception and action, between an object and an actor. When using the information processing metaphor, there may be several processors for perceiving and acting upon objects, but these "processors coconfigure each other" during "an ongoing perception - action coordination" (Clancey, 1993). It is within reality-as-perceived (a psychological reality) that activity occurs, not through abstracted processing of symbols. Connectionism has been recognised as a computational pendant of situated action theories (Bereiter, 1991; cf. Wallner \& Peschl, 1993). However, most connectionistic models still need symbols as input (for a promising model see Brooks, 1991).

At hand, we have a rough, rudimentary theory about situativity and a promise towards its computationability. However, in its present form it fails to describe human activity accurately as it is evident that we use symbols and representations in external as well as in internal forms. No situated action theorist ignores representations or symbols functionally, but present theories lack a satisfying psychological relation between situated action and representation. To obtain this relation, two sorts of representation should be clearly differentiated—as opposed to their conflation in cognitivism: (a) the first-order physical representation which equals the concept of psychological reality in situated action theory, and (b) the second-order physical representation which will be considered a psychological representation. We will use the developmental psychology of Vygotsky (Vygotsky 1987; Vygotsky \& Luria, 1994) to fil the psychological gap between situated action and representation. Two important Vygotskian notions are of particular interest: 
(a) the relation between thought and symbols, and (b) the distinction between everyday concepts and formal concepts. A short outline will now be provided.

The concept of symbols as tools for thought is a compelling and powerful one in situated action theories, but it is important to realise that symbols for everyday concepts (as used in situated action) are not catalysts. During children's development, according to Vygotsky, the use of symbolic tools will change the information-processing (or activation) structure and its possibilities and consequently the meaning of the symbols themselves. During formal concept formation, however, it is assumed that the use of symbols is catalytic: a formal concept does not alter the information processing (or activation) structure.

In their early use of concepts, children try to situate formal concepts. Although this effort is in vain, it enhances children's ability of generalisation (a concrete, situated sort of generalisation, which differs from abstraction). Such generalisations are the basis for 'pseudo concepts', through which students can use the formal concept correctly, although understanding is inaccurate. For example, students may try to situate the formula ' $y=a x+b$ ' by substituting the constants with numbers and the variables with a range of numbers as is possible within the external representation technique used (e.g., a co-ordinate system on a blackboard). The effort will never be successful because the representation of a single instantiation is always inadequate: the line is finite and has a certain thickness. Students learn, but do not understand, that it does not matter how far and thick the line is drawn and that the materials on which the representation is drawn are insignificant. Students may thus acquire a pseudo concept of the formula.

The difference between pseudo concepts and real, formal concepts, Vygotsky argued, is merely a matter of understanding. Eventually, the adolescent will understand abstract, formal concepts. In our view, the crucial understanding does not concern formal concepts itself, instead it is a more general insight that formal concepts are not truly meant to be understood at all, at least not in the sense of the fully affective or situated 
understanding of everyday concepts. This insight opens the way for the adolescent to a pragmatism towards symbols or symbol systems, a tools perspective. The intention and control of formal thinking is well rooted in situated action. This provides formal thinkers with the feeling that they understand what they are doing, even when the meaning of the elements of the process is minimal. The meaning of the result of the thought, a representation, has to be reconstructed, i.e., situated. But this reconstruction is inherently partial.

This particular situated action theory, the developmental situativity theory, (for a complete description see Van der Pal, 1995) provides a psychological relation between situated action and formal symbol systems. For a theory in which perception, action, and cognition are not clearly distinguishable, ‘situativity’ (coined by Greeno \& Moore, 1993) is considered to be a more appropriate label than 'action' or 'cognition'. The term 'development' encompasses both the global structural changes during childhood as well as the specific learning processes.

Implications of the Developmental Situativity Theory for Interactive Graphical Representation Systems for Instruction

An important aspect of an interactive graphical representation is direct manipulation (e.g., Norman, 1986), which means that there is no layer of symbols between the representation to be manipulated and the student (as in old command-line operating systems), but that there is merely a physical tool (e.g., a mouse). Since the manipulator may act towards the representations as if they were real-life objects, the representations will belong to the psychological reality of the manipulator. Therefore, these objects are no longer considered to be representational in a psychological sense. They neither refer to objects in 
the real world nor to abstractions (formal concepts). The (natural) activity towards such objects is at the level of everyday concepts: it is situated.

This is evident for graphical representations of natural objects (having colour, size, depth, etc.). For graphical representations of abstract relations or models, it is less obvious. However, a graph of some relation may become an object for a higher-order situated action (not worked out here) provided that the user already understands the relation of the graph to the formal concepts it represents and to other representations, such as a notated formula.

Situativity in such an environment is in itself not very interesting from an educational point of view (cf. Bereiter's argument that basic-level concepts do not need to be instructed, Bereiter, 1992). The induction of knowledge is easy but will not transcend the psychological reality. This means that everyday concepts may be changed or created during situated activity, but these concepts lack the necessary abstractness for sufficient transfer to other tasks (cf. Norman's discussion about the important but limited use of the experiential mode of thinking, Norman, 1994).

The developmental situativity theory predicts that situated action will benefit from using symbol systems as tools in situations in which everyday concepts are not sufficient for appropriate action. However, formal systems are merely catalytic: they do not work without appropriate situated action. The instructional feedback should apply to situated action that is enhanced by using a formal system. As in fact all activity is situated somehow, this type of situativity will be labelled here as Situativity-in-Domain (SiD).

From a developmental situativity perspective, at least two kinds of IGRSs can be distinguished: (a) systems in which graphics constitute a microworld affording SiD (e.g., Barwise \& Etchemendy's, 1990, Tarski's World), and (b) systems in which graphics are intermediate abstract tools (e.g., systems using Law Encoding Diagrams, Cheng, 1994). The experiment reported below focuses on the IGRS of the first kind, Tarski's World. 
Please insert Figure 1 about here

\section{An Experiment using Tarski's World}

Tarski's World is a computer-based introduction to formal logic. It uses a First-Order Language in which predicates have fixed interpretations, contrary to abstract predicates. The language can be used to formalize statements in natural language about three types of polyhedrons (cubes, tetrahedrons and dodecahedrons), which have properties and relations to each other with respect to spatial positions. Besides this, the user has the possibility to visualize the first-order language in a world. Referring to the interactive graphical representation of the polyhedrons, the natural statements are about everyday concepts and for that matter they can be fully processed in a situated mode. Statements in natural language then are true or false in a specific world. Feedback facilities of Tarski's World can be seen as simulations of the feedback and explanations that logic teachers might provide.

The combination of the interactive graphical representation, the natural language behind the expressions, and the feedback facility allow for SiD. However, instruction facilitating only SiD would not be very powerful as students would not have the necessary tools to be able to work at a more abstract level than that of everyday-concepts. In Tarski's World, students have to work at an intermediate abstract level because they can use the feedback facilities only by making use of the formal component of Tarski's World. Therefore, situative and formal aspects are combined in a tangled way in Tarski's World (see Figure 1).

In order to see whether both situative and formal aspects are necessary for a good understanding of logic, two impaired versions of Tarski’s World will be compared to the complete Tarski's World. The impaired versions will be described below. 
The only-situative version of Tarski's World, TW $\mathrm{SiD}$ (in which feedback is based on invisible formal expressions, see Figure 2), would facilitate learning according to the induction framework (Holland, Holyoak, Nisbett \& Thagard, 1986). Although students receive feedback based on their own graphical representations, it is especially the feedback based on the given graphical representations that confronts students with the logical rules of the 'if - then' statements as opposed to the natural 'if - then' expressions (cf. pragmatic reasoning schemas, Cheng \& Holyoak, 1985). This gives students space to discover the logical rules, a space that students using the only-formal version of Tarski's World, TWF (in which feedback is based on invisible graphical representations, see Figure 3), lack. TW $\mathrm{SiD}$ students have no means or tools other than natural language to abstract from it. It will be very difficult to detach and restructure the pragmatic meaning from the natural sentence without formal tools. Therefore, induction in such an only-SiD environment may require much more feedback than can be provided without harming students' motivation.

It is expected that working with formal tools in a situative environment clears the path to induction beyond the near-transfer level. Therefore, TW instruction is expected to facilitate more logical reasoning on Wason selection tasks than the other two instructions, which will not go much further than a control group will do. This stands in contrast to cognitivistic theories (e.g., the induction framework, Holland et al., 1986), which would not predict a difference between $\mathrm{TW}$ - and $\mathrm{TW}^{\mathrm{SiD}}$-instructions, as one of the two equivalent- linguistic representations is redundant.

Please insert Figure 2 about here

Method

$\underline{\text { Subjects }}$ 
The subjects were 80 first-year technical science students of the University of Twente (63 male, 17 female; mean age 19.4 years, $\mathrm{SD}=1.6$ ) who volunteered for the experiment. Most students reached high math-levels at secondary school, after which they attended some mathematics and computer programming courses.

Materials

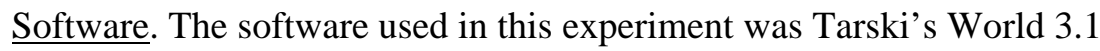
completed by an instructional shell and modified to provide an experimental design. The changes were as follows: (1) for the SiD-condition the sentence window was made invisible (see Figure 2) and for the F-condition the world window was made invisible (see figure 3), (2) the entire text was in Dutch instead of English, (3) menu options were disabled, (4) worlds and sentences were automatically loaded and saved when starting and finishing a task, (5) instructions and tasks were given in a window situated under Tarski’s World, using Hypercard 2.1, (6) demonstrations of basic Tarski’s World operations were given, using the programme Screenrecorder, (7) a help function was added that presented information about every screen element, using Hypercard 2.1, and (8) during the experiment itself the game was disabled.

General Training. The general training included an introduction in first order language and an introduction to Tarski's World with all the aspects that could be used.

Treatment. The subjects in the SiD\&F, SiD and F condition received a text about the material conditional (see Appendix A). They also had to practise with six problems that consisted of 18 sentences together. The explanatory text about the material condition has partly been derived from the text that Cheng et al. (1986) used in the rule training condition of their experiment 1 , and partly derived from the text about the conditional in 
the book that goes with Tarski's World (Barwise \& Etchemendy, 1990). The six exercises all focused on the material conditional. The subjects in the control condition received neither the text nor the problems.

$\underline{\text { Tests. }}$ There were three tests: a pretest, a posttest and a follow up. All three consisted of four arbitrary Wason selection tasks (Wason, 1966). For an example, see Appendix B.

\section{Procedure}

The subjects were randomly assigned to one of four conditions: (1) SiD\&F-condition in which there was situated instruction as well as formal instruction, (2) SiD-condition with only situated instruction, (3) F-instruction with only formal instruction, and (4) Ccondition (control group) without any instruction besides the general training. The experiment was held in two sessions. Sessions took place in groups of at most five students in which all subjects worked individually. The first session took about three to five hours. The students had to do the pretest consisting of four arbitrary Wason selection tasks. Then all subjects received the general training in which they learned to work with the programme and received the introduction in logic. After this training, subjects in the control group immediately had to do the posttest consisting of four similar Wason selection tasks. The other three groups received the instructional treatment which consisted of the explanatory text about the material conditional and the six Tarski's World problems containing 18 sentences in natural language. After this instruction, the subjects in the experimental groups had to do the same posttest as the control group. A week later, the follow-up assessment took place. In this session which lasted approximately five minutes, the subjects only had to solve the four Wason selection tasks. 
Please insert Figure 3 about here

Please insert Figure 4 about here

Results

$\underline{\text { Immediate effects (posttest - pretest) }}$

The overall increase in PAC (Percentage All items Correct) is 16\% (19\% - 3\%, see Figure 4 or Table 1), which is significant, McNemar binomial test $\mathrm{p}<.001$. However, for individual groups, differences were significant only for the SiD\&F-group (30\% improvement), McNemar test, $\mathrm{p}<.05$, one-tailed. Differences in PAC increase between all groups were not significant, Kruskal-Wallis $\chi^{2}=4.63, \mathrm{p}=.20$. Comparing individual groups revealed only a significant difference between the SiD\&F-group and the Control group in favour of the SiD\&F-group (25\% difference in gain), $\chi^{2}=4.22, \mathrm{p}<.05$.

Please insert Table 1 about here

Parametric analysis (repeated measures with contrasts for comparing individual groups) can be done by using the logic index (Pollard \& Evans, 1987), which indicates the number of falsifying selections (P or NOT-Q, when the rule has the form of "If P then 
Q”) relative to non-falsifying selections (NOT-P or Q). ${ }^{1}$ Logic indices (see Table 2) showed the same pattern as PAC (using repeated measures with contrasts for comparing individual groups). The overall increase of the logic index was 0.31 points, $F(1,76)=$ 19.48, $\mathrm{p}<.001$. No significant gain-difference was found between all groups, $F(3,76)=$ $1.11, \mathrm{p}=.35$. Comparing individual groups, only the 0.36 points gain-difference between the SiD\&F-group and the C-group was found to be significant, $\mathrm{F}(1,76)=3.28, \mathrm{p}<.05$.

Please insert Table 2 about here

Delayed effects (follow-up - pretest)

The $25 \%$ overall gain in PAC (see figure 4 or Table 1 ) was significant, McNemar test, $\mathrm{p}$ $<$.001. Improvement for individual groups was significant for the SiD\&F-group (50\%), McNemar test, $\mathrm{p}<.001$, one-tailed. The $20 \%$ improvement for the SiD-group was not significant, McNemar test, $\underline{\mathrm{p}}=.06$, one-tailed. PAC-increase differs between groups, $\chi^{2}=$ $9.40, \underline{\mathrm{p}}<.05$. This difference can be attributed to differences between the SiD\&F-group and the other groups: SiD\&F versus $\mathrm{SiD}$ and $\mathrm{SiD} \& \mathrm{~F}$ versus $\mathrm{F}$ (resp. $30 \%$ and $35 \%$ more gain for the SiD\&F-group) $\chi^{2}>3.85, \mathrm{p}<.05$; SiD\&F versus C (40\% more gain for the SiD\&F-group) $\chi^{2}=7.43, \underline{\mathrm{p}}<.01$. Differences in PAC increase between SiD, F, and C groups were not significant, $\chi^{2}<.77$.

The overall increase on the logic indices was 0.46 points (see Table 2), which was significant, $\underline{\mathrm{F}}(1,76)=51.75, \mathrm{p}<.001$. Comparing individual groups, it was found

\footnotetext{
${ }^{1}$ The logic index specifically scores +1 for a P or NOT-Q selection and -1 for a NOT-P or a $Q$ selection. This produces a 5-point scale from -2 to 2 . The logic index can be seen as the extent to which the choices agree with logical choices, but as Pollard and Evans point out, it does not measure any personal logical ability, strategy or insight. The logic index is particularly useful for its potential to measure a change in response other than incorrect - correct. For instance, the improvement of a NOT-P and Q choice to a P choice is considerable (3 points on the 5-point scale), but PAC and the number of correct responses are insensitive to it.
} 
that $\mathrm{SiD} \& \mathrm{~F}$ versus $\mathrm{SiD}$ and $\mathrm{SiD} \& \mathrm{~F}$ versus $\mathrm{F}$ differences in gain (resp. .38 and .39 points more increase for the SiD\&F-group) were significant at the 5\% level, $F(1,76)>4.31$, and that the SiD\&F versus C difference ( 0.46 points more increase for the SiD\&F-group) was significant at the $1 \%$ level, $\underline{F}(1,76)=6.21$. Differences in increase on the logic index between SiD, F and C groups were not significant, $\underline{\mathrm{F}}(1,76)<.18$.

\section{Discussion}

As hypothesised, the results revealed a facilitating effect of the complete Tarski's World instruction on the Wason selection tasks, immediately after the treatment and even stronger after a week (50\% of the students in the SiD\&F-group did all items correct against $15 \%$ of the control group). It is unclear why the delayed effect was stronger than the immediate effect. Conform the hypotheses, only-SiD instruction and only-formal instruction did not enhance logical reasoning, compared to the control group. These findings illustrate the importance of a combined SiD and formal instruction. An only-SiD instruction is not effective, because it lacks the tools to abstract from the experiences beyond the near-transfer level. This demonstrates the incompleteness of cognitivist theories like the induction framework of Holland et al. (1986). An only-formal instruction is not effective as it only provides tools without the situations in which the tools can be used in a relevant way.

This study signifies the importance of Interactive Graphical Representations when used in combination with formal systems for logic instruction. As logic may not be prototypical due to its abstract subject, it may be objected that the conclusion — formal tools are needed during SiD— can be generalised to other domains. This criticism appears to find additional support in many instructional practices in which it is apparently sufficient only to act directly on the matter (situated learning) for which purpose IGRSs may be developed, or to act merely by using formal symbols (formal education). 
Although these learning effects are not contradicted, they are considered to be uninteresting for educational purposes. Most learning processes in everyday life are situated, with concrete-symbolic, situative tools (everyday or basic-level concepts). Bereiter (1992) argues that it is not necessary to teach basic-level concepts as they are learned without much effort in everyday life. Instruction that is totally based on situated learning, therefore, is a waste of time and effort. Formal symbols (referring to abstract concepts) are useful as tools just because they lack situativity. Even without dual stimulation (situated \& formal), some bright students may be able to play with formal systems quite handsomely on near-transfer tasks, without really knowing what they do and why they do it; they act on the pseudo-conceptual level. For these students, formal education seems successful, but what is likely to happen is that they learn to operate tools without understanding. As these students are bright, they may eventually understand the use of these tools in further education or in their jobs, but such a learning process is not efficient and it is ineffective for other students.

Unfortunately, this argument does not make instructional design easier. For instance, it implies the importance of another Vygotskian concept, the 'zone of proximal development' in which instruction is only effective and efficient when the student may be able to understand a concept or to perform a task with some help.

The finding that a certain type of IGRS has a necessary but insufficient functionality for a certain type of learning is important in itself -if only because of the unprecedented learning effect for abstract conditional reasoning- but it fails to demonstrate a precise relation between instruction and learning. The instructional guidelines distiled from situated cognition notions may often be inaccurate or invalid (Anderson et al., 1996), but the developmental situativity theory needs a layer of more specific learning models before an alternative set of guidelines with sufficient specificity can be produced. 


\section{References}

Anderson, J.R., Reder, L.M. \& Simon, H.A. (1996). Situated learning and education. Educational Researcher, 25(4), 5-11.

Barwise, J. \& Etchemendy, J. (1990). The language of first-order logic. Stanford: Center for the Study of Language and Information.

Bereiter, C. (1991). Implications of connectionism for thinking about rules. Educational Researcher, 20 (3), 10-16.

Bereiter, C. (1992). Referent-centred and problem-centred knowledge: Elements of an educational epistemology. Interchange, 23(4), 337-362.

Bereiter, C. (1995). Beyond situated cognition. Invited address at the $6^{\text {th }}$ European Conference for Research on Learning and Instruction, August 26-31, 1995, EARLI, Nijmegen.

Brooks, R.A. (1991). How to build complex creatures rather than isolated cognitive simulators. In K. van Lehn (Ed.): Architectures for Intelligence: The 22nd Carnegie Symposium on Cognition. Hillsdale, NJ: Erlbaum.

Brown, J.S., Collins, A. \& Duguid, P. (1989). Situated cognition and the culture of learning. Educational Researcher, 17, 32-41.

Cheng, P.C.-H. (1994). Law Encoding Diagrams for instruction (Tech. rep. 6). ESRC: University of Nottingham.

Cheng, P.W. \& Holyoak, K.J. (1985). Pragmatic reasoning schemas. Cognitive Psychology, 17, 391-416.

Cheng, P.W., Holyoak, K.J., Nisbett, R.E. \& Oliver, L.M. (1986). Pragmatic versus syntactic approaches to training deductive reasoning. Cognitive Psychology, $\underline{18}$, 293328. 
Choi, J.-I. \& Hannafin, M. (1995). Situated cognition and learning environments: roles, Structures, and implications for design. Educational Technology: Research \& Development, $\underline{43}(2), 53-69$.

Clancey, W.J. (1993). Situated action: A neuropsychological interpretation response to Vera and Simon. Cognitive Science, 17(1), 87-118.

Evans, J.St.B.T., Newstead, S.E. \& Byrne, R.M.J. (1993). Human reasoning: The psychology of deduction. Hove, UK: Lawrence Erlbaum Association.

Greeno, J.G. (1990). Productive learning environments. Proceedings of the International Conference on Advanced Research on Computers in Education (pp. 1-11). Tokyo, Japan.

Greeno, J.G. \& Moore, J.L. (1993). Situativity and symbols: Response to Vera and Simon. Cognitive Science, 17(1), 49-60.

Greeno, J.G., \& The Middle School Mathematics Through Application Project Group (1998). The situativity of knowing, learning, and research. American Psychologist. $\underline{53}(1), 5-26$.

Holland, J.H., Holyoak, K.J., Nisbett, R.E. \& Thagard, P.R (1986). Induction: Processes of inference, learning, and discovery. Cambridge, MA: The MIT Press.

Norman, D.A. (1986). Cognitive engineering. In D.A. Norman \& S.W. Draper (Eds), User centered system design: New perspectives in human-machine interaction (pp. 3161). Hillsdale, London: Lawrence Erlbaum Associates.

Norman, D.A. (1994). Things that make us smart. In: D.A. Norman (Ed.), Defending human attributes in the age of the machine (CD-ROM). New York: Voyager.

Van der Pal, J. (1995). The balance of situated action and formal instruction for learning conditional reasoning. Doctoral dissertation, University of Twente, Enschede.

Vygotsky, L.S. (1987). Thinking and speech. In R. Rieber \& A.S. Carton (Eds.), The collected works of L.S. Vygotsky. Vol 1. Problems of general psychology. New York: Plenum Press. (Original work published 1934) 
Vygotsky, L.S. \& Luria, A. (1994). Tool and symbol in child development. In R. van der Veer \& J. Valsiner (Eds.), The Vygotsky Reader (pp. 99-174). Oxford: Blackwell.

Wallner, F. \& Peschl, M. (1993). Cognitive science - an experiment in constructive realism; constructive realism - an experiment in cognitive science. In: C. van Dijkum \& G. de Zeeuw (Eds.), Methodological explorations in constructive realism (pp. 3039). Amsterdam: Sokrates Science Publisher.

Wason, P.C. (1966). Reasoning. In B.M. Foss (Ed.), New horizons in psychology. Harmondsworth: Penguin. 
Appendix A: The Explanatory Text about the Material Conditional (translated from Dutch)

The symbol for the material conditional $(\rightarrow)$ is used to combine two sentences P and Q to form a new sentence $\mathrm{P} \rightarrow \mathrm{Q}$. Such a sentence is called a material conditional. The sentence $\mathrm{P}$ is called the antecedent of the conditional, and Q is called the consequent. The logical meaning of $\mathrm{P} \rightarrow \mathrm{Q}$ is more rigid than the meaning of conditionals in everyday Dutch. In natural language, $\mathrm{P}$ always has a sensible relation to $\mathrm{Q}$. This is not necessary in logic. The truth value of a material conditional is determined only by the truth values of the antecedent and the consequent. This is why the conditional is called material. To put it differently: The logical meaning of a conditional is an abstraction of the natural meaning. A text follows which clarifies the material conditional. Try to understand the material conditional and try to apply it to the tasks that will be presented after the text. We can come fairly close to an adequate Dutch rendering of the expression $\mathrm{P} \rightarrow \mathrm{Q}$ with the sentence If $\mathrm{P}$ then $\mathrm{Q}$. Other Dutch sentences that may be translated to $\mathrm{P} \rightarrow \mathrm{Q}$ are: $\mathrm{Q}$ provided P, P only if Q, and Q when P. At any rate, it is clear that Dutch conditionals, like the material conditional is false if $\mathrm{P}$ is true and $\mathrm{Q}$ is false. A sentence as: If Wim is at home, then Linda is at the library can be translated into: Home(Wim) $\rightarrow$ Library(Linda). Dutch expressions of the form All A's are B's and Every A is a B can be translated into: $\forall \mathrm{x}(\mathrm{A}(\mathrm{x}) \rightarrow \mathrm{B}(\mathrm{x}))$. In logic, this sentence is true when any object either fails to be an $\mathrm{A}$ or else be a B. Let P stand for "It is raining." and let Q stand for "The pavement is wet." Then $\mathrm{P} \rightarrow \mathrm{Q}$ says "If it is raining, then the pavement is wet." This expression is equivalent to $\neg \mathrm{Q} \rightarrow \neg \mathrm{P}$, saying "If the pavement is not wet, then it is not raining." A way of understanding this equivalence is through the concept of sets. Sets can be represented by Euler diagrams. (Consult the experimenter when the diagrams are not clear.) Let $\mathrm{P}$ stand for "Something is an element in the set of oranges (S)." and let Q stand for "Something is an element in the set of citrus fruits (C)." Then $\mathrm{P} \rightarrow \mathrm{Q}$ means "If 
something is an orange, then it is also a citrus fruit." It is evident that this statement is equivalent to "If something is not a citrus fruit, then it is not an orange either." It will be equally evident that $\mathrm{P} \rightarrow \mathrm{Q}$ is not equivalent to $\mathrm{Q} \rightarrow \mathrm{P}$ ("If something is a citrus fruit, then it will also be an orange.") This also holds good for statements concerning overlapping sets. Consider the conditional "If something is a sports car (S), then its colour is red (R)." This statement is only false when elements exist in the white part of the diagram. Now, a black sports car x has been observed. Therefore, car x falls in the white part of the diagram. The conditional is false. Everybody knows this, but if someone would not know a thing about cars, then the truth value of the statement could be found by watching out for sports cars and for other than red cars. 
Appendix B: Text of one of the used Wason selection tasks (translated from Dutch)

Below are four cards. On each card a letter is printed on one side of the card and a number on the other side. A card never contains two numbers or two letters. Hypothesis: If there is an A on one side of the card, there is a 2 on the other side. Which of the cards below do you have to turn to decide whether the hypothesis is true or false? Click only on the card(s) that is (are) needed for your decision. Note that the clicked cards will become black. If you want to undo a choice, just click again on the card. 
Table 1

Percentages All items Correct (PAC) for each condition

\begin{tabular}{lcccc}
\hline & \multicolumn{4}{c}{ Condition } \\
\cline { 2 - 5 } & SiD\&F & SiD & F & C \\
\hline pretest & 0 & 0 & 5 & 5 \\
posttest & 30 & 15 & 20 & 10 \\
follow-up & 50 & 20 & 20 & 15 \\
\hline
\end{tabular}

Note. $\mathrm{SiD}=$ Situativity-in-Domain, $\mathrm{F}=$ formal, $\mathrm{C}=$ Control. $\mathrm{n}=20$ for each group. 
Table 2

Mean logic indices and standard deviations (between parentheses)

for each condition

\begin{tabular}{lcccc}
\hline & \multicolumn{5}{c}{ Condition } \\
\cline { 2 - 5 } & SiD\&F & SiD & $\mathrm{F}$ & $\mathrm{C}$ \\
\hline pretest & $.71(.70)$ & $.74(.30)$ & $.76(.67)$ & $.70(.55)$ \\
posttest & $1.21(.65)$ & $1.06(.51)$ & $1.05(.59)$ & $.84(.63)$ \\
follow-up & $1.48(.60)$ & $1.13(.59)$ & $1.14(.59)$ & $1.01(.63)$ \\
\hline
\end{tabular}

Note. $\mathrm{SiD}=$ Situativity-in-Domain, $\mathrm{F}=$ formal, $\mathrm{C}=$ Control. $\mathrm{n}=20$ for each group. The logic index ranges from -2 to 2 . 


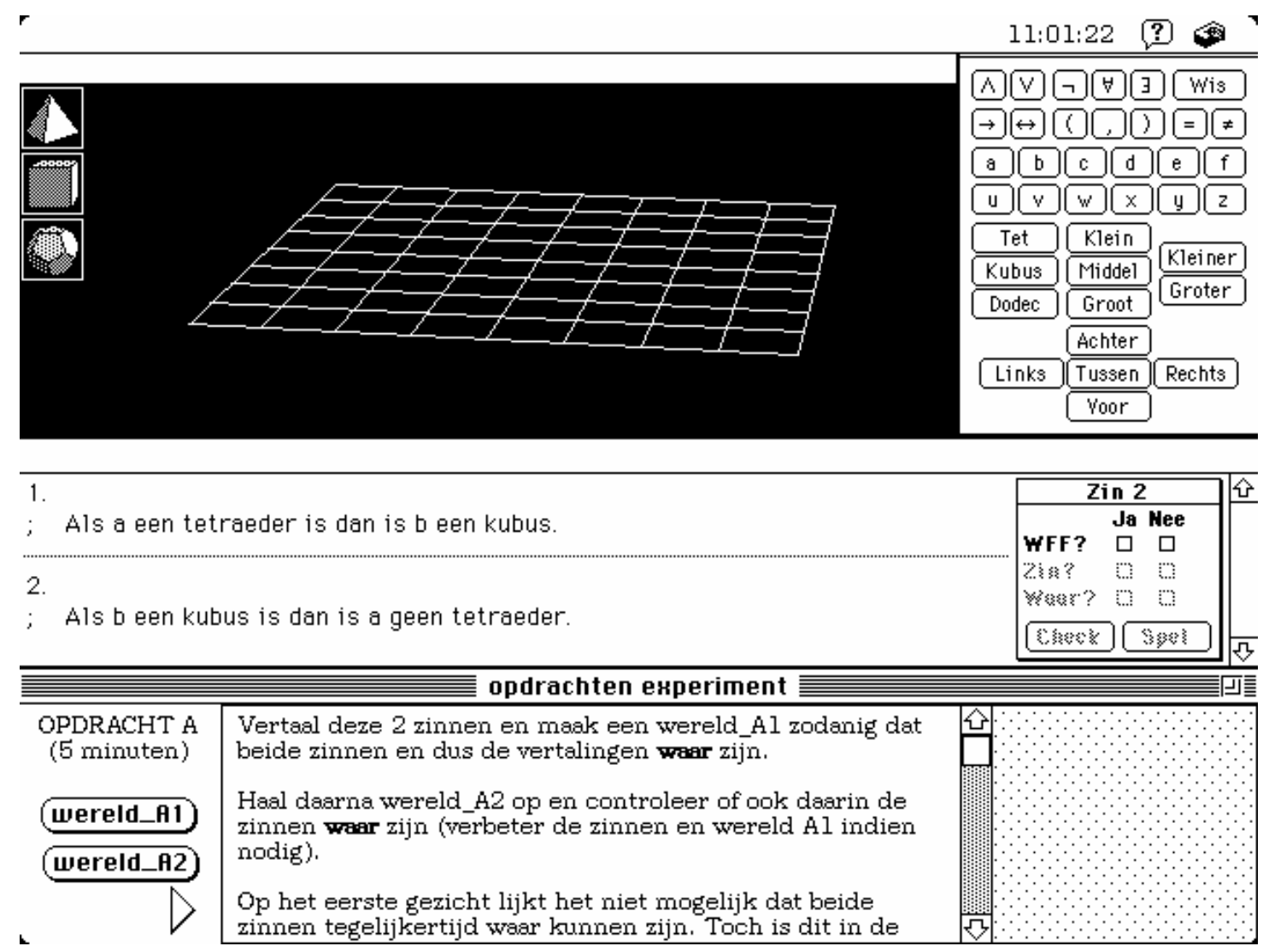

Figure 1. Example of a task in the $\mathrm{TW}^{\mathrm{SiD} \& \mathrm{~F}_{\text {-condition. }}{ }^{2} \text { The top three windows belong }}$

to the Dutch research version of Tarski's World 3.1. The lower window belongs to the instructional shell for the experiment.

\footnotetext{
${ }^{2}$ Translation of task instructions (note that World_A2 contains only a small dodecahedron with names a and b): Translate the two sentences and construct a world_A1 in which both Dutch sentences are true. Then go to world_A2 and verify whether the expressions are true (If necessary, correct your translations and world_A1). At first sight it may appear that the sentences cannot be true at the same time. Nevertheless, this is the case in logic. Try to understand why. Sentence 1: If $\mathrm{a}$ is a tetrahedron then $\mathrm{b}$ is a cube. Sentence 2: If $\mathrm{b}$ is a cube, then a is not a tetrahedron.
} 


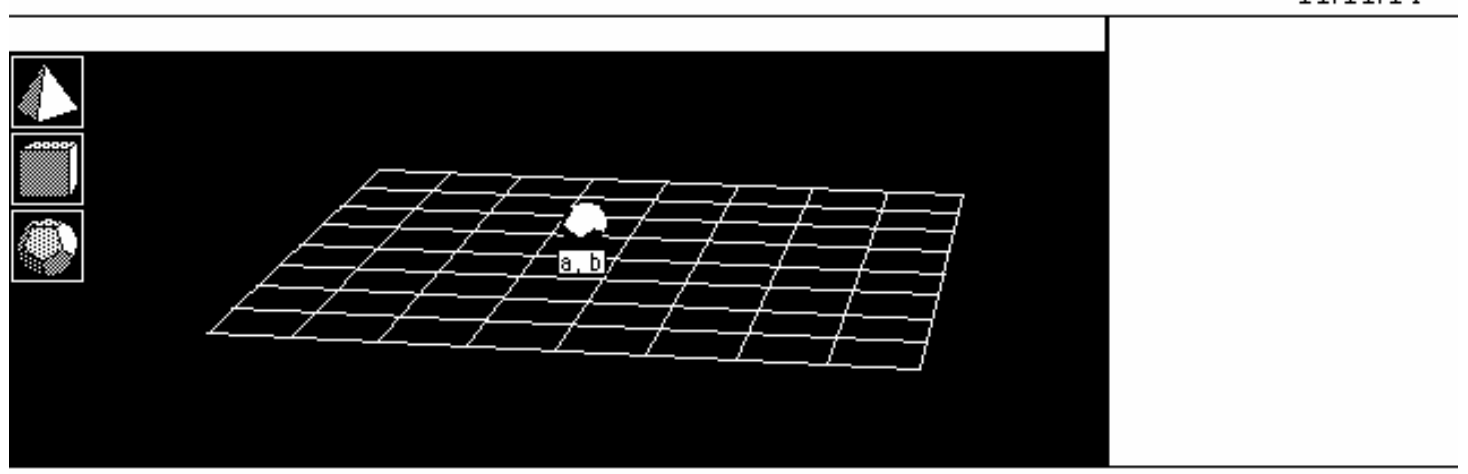

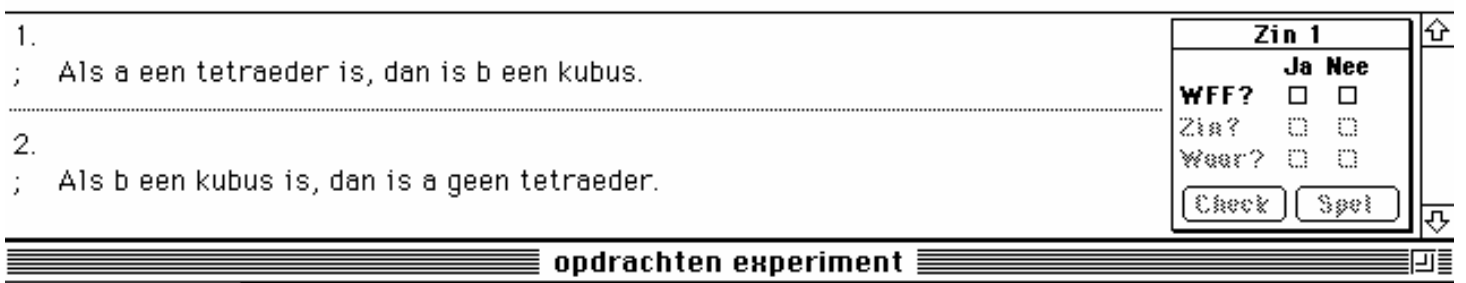

\begin{tabular}{|c|c|}
\hline $\begin{array}{l}\text { OPDRACHT A } \\
\text { (5 minuten) }\end{array}$ & $\begin{array}{l}\text { Maak een wereld_Al zodanig dat beide Nederlandse zinnen } \\
\text { waar zijn. }\end{array}$ \\
\hline wereld_A1 & $\begin{array}{l}\text { Haal daarna wereld_A2 op en controleer of ook daarin de } \\
\text { zinnen war zijn (verbeter wereld Al indien nodig). }\end{array}$ \\
\hline wereld_A2 & $\begin{array}{l}\text { Op het eerste gezicht lijkt het niet mogelijk dat beide } \\
\text { zinnen tegelijkertijd waar kunnen zijn. Toch is dit in de } \\
\text { logica het geval. Probeer te begrijpen waarom. }\end{array}$ \\
\hline
\end{tabular}

Figure 2. Example of an experimental task in the $\mathrm{TW} \mathrm{SiD}_{\text {-condition. }}{ }^{3}$

${ }^{3}$ Translation of task instructions: Construct a world_A1 in which both Dutch sentences are true. Then go to world_A2 and verify whether the expressions are true either (If necessary, correct world_A1). At first sight it may appear that the sentences cannot be true at the same time. Nevertheless, this is the case in logic. Try to understand why. Sentence 1: If a is a tetrahedron, then $b$ is a cube. Sentence 2: If $b$ is a cube then $a$ is not a tetrahedron. 


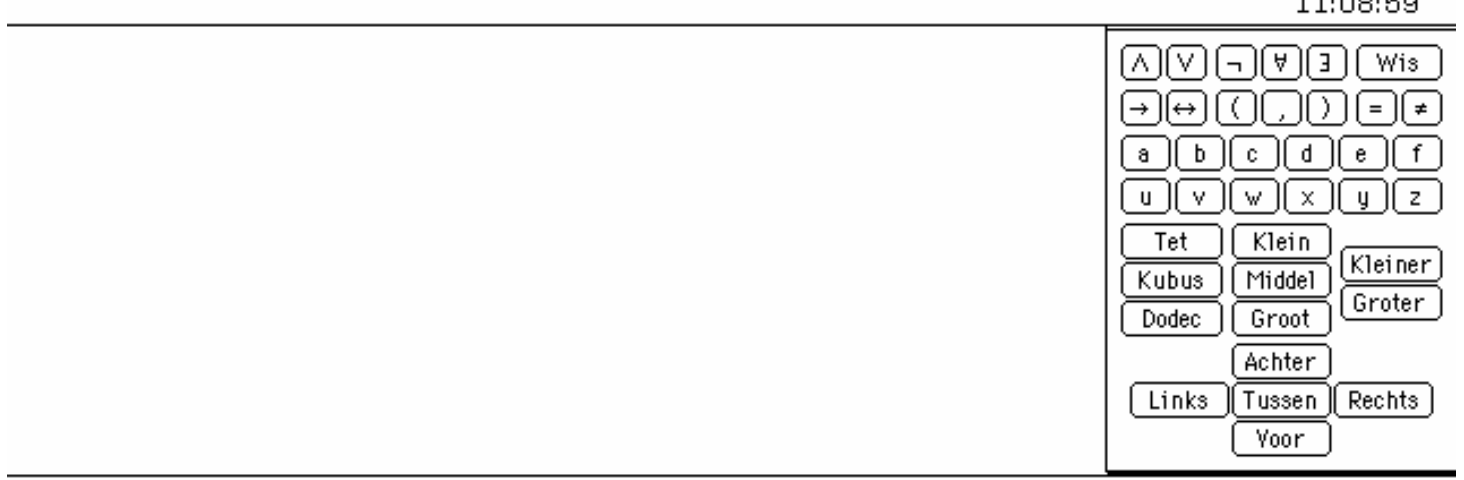

1. Als a een tetraeder is dan is b een kubus.
2. Als b een kubus is dan is a geen tetraeder.

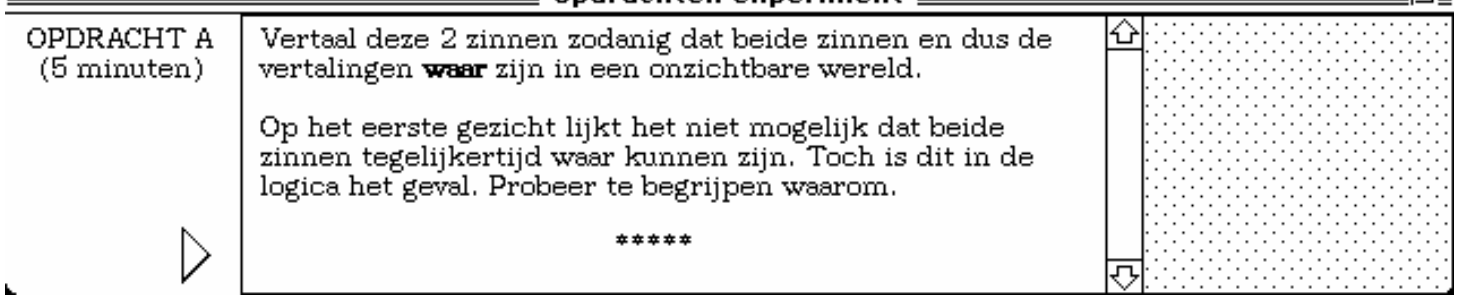

Figure 3. Example of a task in the $\mathrm{TW}^{\mathrm{F}}$-condition. ${ }^{4}$

${ }^{4}$ Translation of task instructions (note that the invisible world contains only a small dodecahedron with names a and b): Translate the two sentences. They should be true in the invisible world. At first sight it may appear that the sentences cannot be true at the same time. Nevertheless, this is the case in logic. Try to understand why. Sentence 1 : If a is a tetrahedron then $b$ is a cube. Sentence 2: If $b$ is a cube then $a$ is not a tetrahedron. 


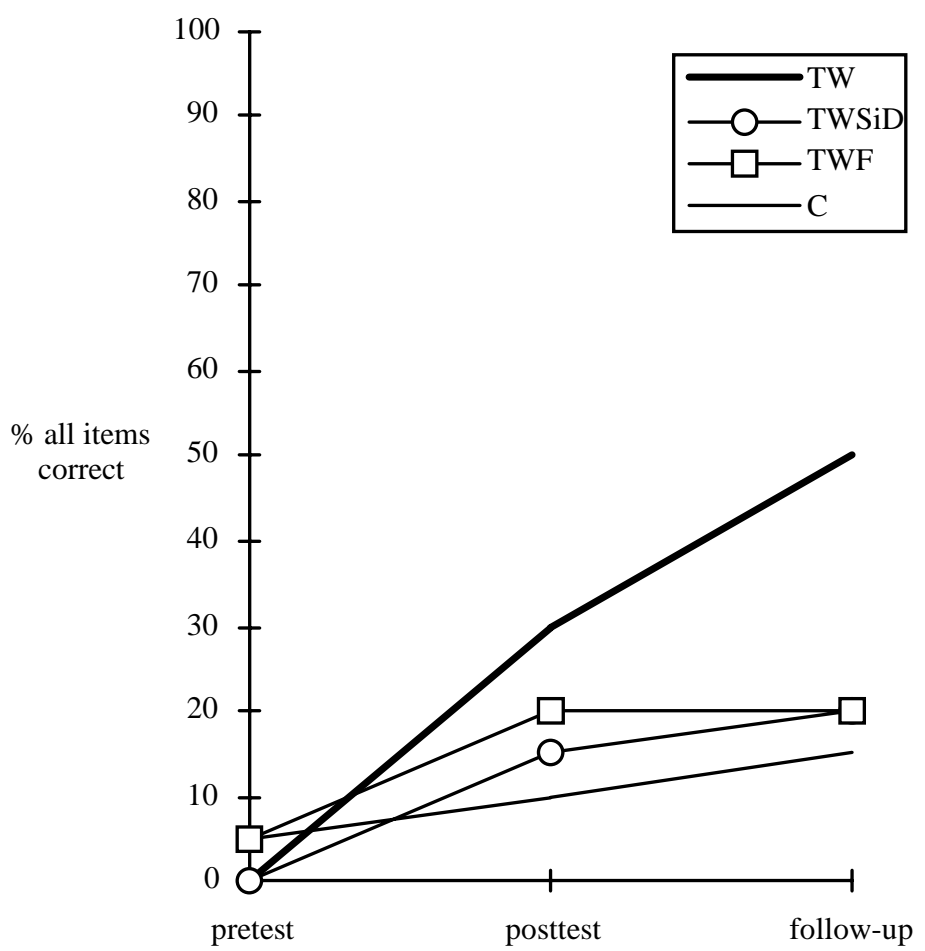

Figure 4. Percentages all Wason selection tasks correct (PAC) for the four conditions. 